\title{
Laboratory Determination of Coal Dust Cleaning Efficacy of a Fibrous Filter for Flooded-Bed Dust Scrubber
}

\author{
Neeraj Gupta ${ }^{1, *}$, Ashish Ranjan Kumar ${ }^{2, *}$ and Steven Schafrik ${ }^{1}$ \\ 1 Department of Mining Engineering, University of Kentucky, Lexington, KY 40508, USA; \\ steven.schafrik@uky.edu \\ 2 Department of Mining and Nuclear Engineering, Missouri University of Science and Technology, \\ Rolla, MI 65409, USA \\ * Correspondence: neeraj.gupta24@uky.edu (N.G.); arkxnf@mst.edu (A.R.K.)
}

Citation: Gupta, N.; Kumar, A.R.; Schafrik, S. Laboratory Determination of Coal Dust Cleaning Efficacy of a Fibrous Filter for Flooded-Bed Dust Scrubber. Minerals 2021, 11, 295. https://doi.org/10.3390/min11030295

Academic Editor: Emily Sarver

Received: 9 February 2021

Accepted: 9 March 2021

Published: 11 March 2021

Publisher's Note: MDPI stays neutral with regard to jurisdictional claims in published maps and institutional affiliations.

Copyright: (C) 2021 by the authors. Licensee MDPI, Basel, Switzerland. This article is an open access article distributed under the terms and conditions of the Creative Commons Attribution (CC BY) license (https:// creativecommons.org/licenses/by/ $4.0 /)$.

\begin{abstract}
Fibrous-type dust filters are used in flooded-bed dust scrubbers to capture dust from underground room and pillar mining atmospheres. They have 10-30 layers of finely woven strands that trap particles through the interception and impaction process. A full-cone water spray is installed upstream of the filter, which floods the screen. A scrubber's efficacy is usually measured and reported in terms of reduction in gravimetric dust concentration at a known location in a mine. This paper reports the particle-size-dependent dust removal efficiency of a fibrous filter obtained from an instrumented test-set up. A variable frequency drive and an inline flow control knob were used to control the airflow through the filter and water flow onto the filter. Optical particle counting of coal dust particles upstream and downstream was carried out to determine the cleaning efficacy. Experiments showed an increase in cleaning efficiency for all the dust particles with their size. A progressive decrease in dust concentration downstream of the filter with an increase in water flow through the nozzle affirmed the capture of dust particles by water sprays.
\end{abstract}

Keywords: fibrous dust filter; dust scrubber; coal worker's pneumoconiosis; aerosol dynamics; optical particle counting; iso-kinetic sampling

\section{Introduction}

Dust produced in mining operations is detrimental for the health of the personnel involved. Research has conclusively shown that prolonged inhalation of respirable dust leads to an onset of irreversible breathing-related ailments [1]. Coal workers' pneumoconiosis, also known as black lung, is potentially fatal with no decisive cure known [2-4]. Other industries including construction are also impacted by dust exposure to persons resulting in diseases including asbestosis $[5,6]$. Float dust can travel distances much further away from the generation source [7]. Deposited dust also shows a varied particle size range and characteristics [8]. Research at the National Institute for Occupational Safety and Health, United States on dust sampled in ten coal mines showed a primary mode size of about $17.0 \mu \mathrm{m}$ and secondary size of about $5.0 \mu \mathrm{m}$ [9]. Dust concentration beyond a critical concentration could also endanger the safety of the processes. Coal dust explosions have led to loss of lives and operations [10-12].

Mining operations use a variety of corrective actions including ventilation systems to combat dust. Other dust suppression measures include water sprays and curtains, which form a barrier between the dust source and the persons. They were recently designed to suppress dust from longwall returns [13]. Research has shown that microscopic water droplets also can remove aerosols from the airstream [14]. The University of Kentucky developed a novel Vortecone scrubber for capturing automobile paint particles of up $300.0 \mu \mathrm{m}$ in size. Particle-laden air is brought into the filter and accelerated to differentially alter the particle trajectory to remove the particles $[15,16]$. Later, the Vortecone was adapted to capture coal dust particles in the size range of 2.0-10.0 $\mu \mathrm{m}$ [17-19]. Computer models 
followed by laboratory testing showed the Vortecone to trap $75 \%$ of coal dust particles of $2.8 \mu \mathrm{m}$ and $90 \%$ of particles exceeding $4.7 \mu \mathrm{m}$ in size. A modified Vortecone was later developed for horizontal implementation. This filter showed excellent cleaning efficiency of coal and limestone particles in airflows up to $0.94 \mathrm{~m}^{3} / \mathrm{s}$ in the laboratory experiments [20].

A flooded-bed dust scrubber is a mechanical dust-capturing system that was invented in 1983 [21]. This is now a standard device installed on the continuous miner and is effective in removing dust efficiently on $6.0 \mathrm{~m}$ deep sections [22]. These scrubbers also enable fresh air to reach close to the active mining face. Experiments have also shown the silica dust concentration to diminish with the scrubber application [23]. These scrubbers have a multi-layered fibrous screen filter, which is the primary dust cleaning element. Spraying action enhances particle capture from the airstream and alleviates filter clogging. This is followed by a demister that removes water droplets. A vane axial flow fan is the primary air mover. Recent advances in flooded-bed dust scrubber research include the development of one customized for longwall shearers [24].

Research on flooded-bed dust scrubbers has shown their efficacies in lowering the dust concentration at known positions underground in controlled tests. However, these are expressed in terms of gravimetric reductions. Heavier components of the dust are captured easily and could lead to masking of cleaning efficacies for smaller particles. Moreover, these fibrous filters are known to get clogged due to the continuous deposition of dust [25]. This impacts the scrubber performance and dust particle cleaning profile. Scrubber operations with a clean functional filter operating at a fixed flow are also critical to bringing fresh air up to the active mining face $[26,27]$. A clogged fibrous filter would lead to lower airflow towards the face; this might not be sufficient for the dilution of coal dust being generated at the face. This paper reports the performance of a clean 20-layered fibrous filter sourced from an underground coal mine. Total pressure and static pressure values were recorded at known airflows to determine the filter resistance. This was followed by optical particle counting experiments using coal dust particles to determine the cleaning efficiency for different particle sizes.

\section{Materials and Methods}

An instrumented test-set up was designed and constructed within the mine ventilation laboratory at the University of Kentucky. This was built as a generic modular set-up to enable performance testing of any mining filters for airflows up to about $2.8 \mathrm{~m}^{3} / \mathrm{s}$.

\subsection{Construction of Duct and Filter Housing}

A centrifugal fan operated using a variable frequency drive was used to control the airflow precisely through the filter. This was connected to a $2.4 \mathrm{~m}$ long duct whose crosssection measured $0.45 \mathrm{~m} \times 0.30 \mathrm{~m}$. This was followed by a Dwyer pressure measurement station equipped with airflow straighteners. This instrumentation allowed an accurate measurement of total and static pressure. The two ports on the device were connected to a digital pressure gauge manufactured by TSI. The pressure measurement station was followed by a duct with vane and rail arrangement to lower the undesirable pressure drop due to shock losses at the corners. A wider duct as shown in Figure 1a with $0.66 \mathrm{~m} \times 0.36 \mathrm{~m}$ in dimensions was constricted to enable mounting of the dust filters at $45^{\circ}$, which mimics the industry-wide practice. Figure $1 \mathrm{~b}$ shows the 20-layered fibrous filter installed. A fullcone water spray was mounted upstream of the filter to flood the surface. This enhances the probability of particle impaction on the fibrous surface in addition to alleviating clogging of the filter. Air discharged downstream was directed towards a dust removal system connected to the building ventilation system. This lowered the exposure of research personnel to the coal dust.

The centrifugal fan was operated at a known frequency and all leakages were sealed off using duct tape. The frequency on the variable frequency drive was then set at $10.0 \mathrm{~Hz}$ and total and static pressures were recorded. Flow pressure obtained was used to compute the average velocity and the quantity in the duct. The frequency was increased in steps 
of $10.0 \mathrm{~Hz}$ until $50.0 \mathrm{~Hz}$ and the exercise was repeated three times to obtain a good representative average. A linear dependence of average airspeed to the variable frequency drive (VFD) frequency was obtained as shown in Figure 2a and agrees with the established fan law. A curve of best fit following Atkinson's quadratic dependence of pressure on the airflow was generated and is shown in Figure $2 \mathrm{~b}$. The flow $(\mathrm{Q})$ pressure-drop $(\mathrm{P})$ relationship is shown in Equation (1). A resistance (R) value of $126.327 \mathrm{Ns}^{2} / \mathrm{m}^{8}$ was obtained. These plots will be used to locate the pressure drop and corresponding frequency on the VFD quickly for filter efficiency testing.

$$
P=126.327 Q^{2}
$$

where $\mathrm{P}(\mathrm{Pa})$ and $\mathrm{Q}\left(\mathrm{m}^{3} / \mathrm{s}\right)$ indicate the total pressure drop and volumetric flow rate through the filter, respectively.

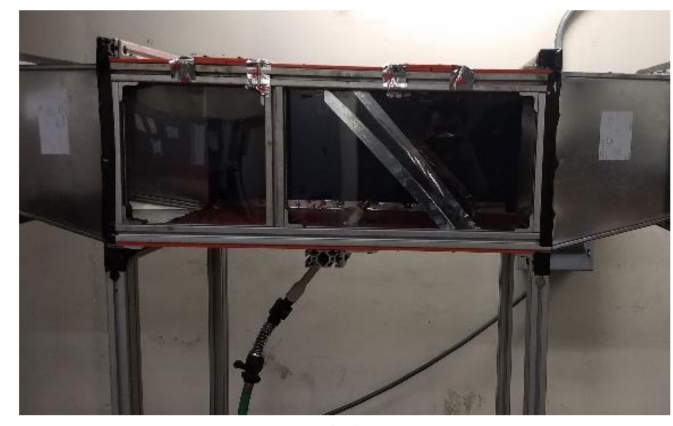

(a)

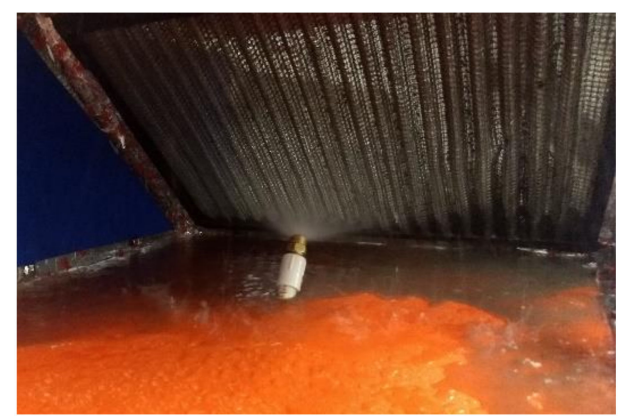

(b)

Figure 1. (a) Set-up for installation of dust filters for performance testing; (b) fibrous dust filter with water spray operational.

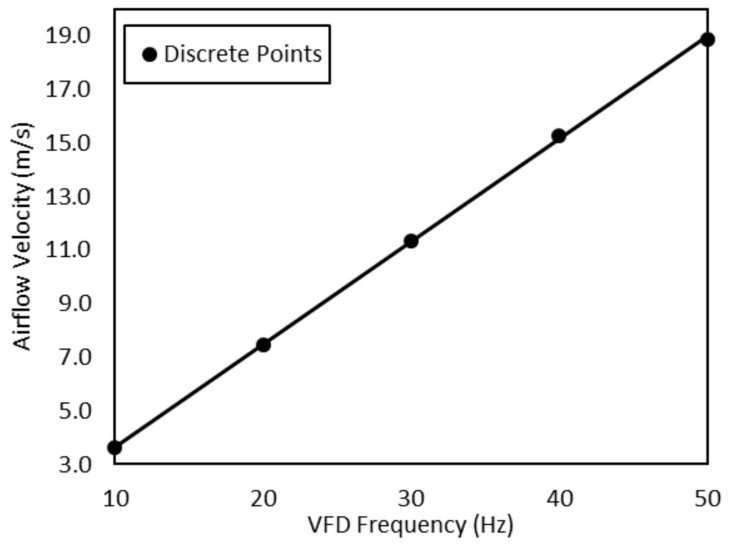

(a)

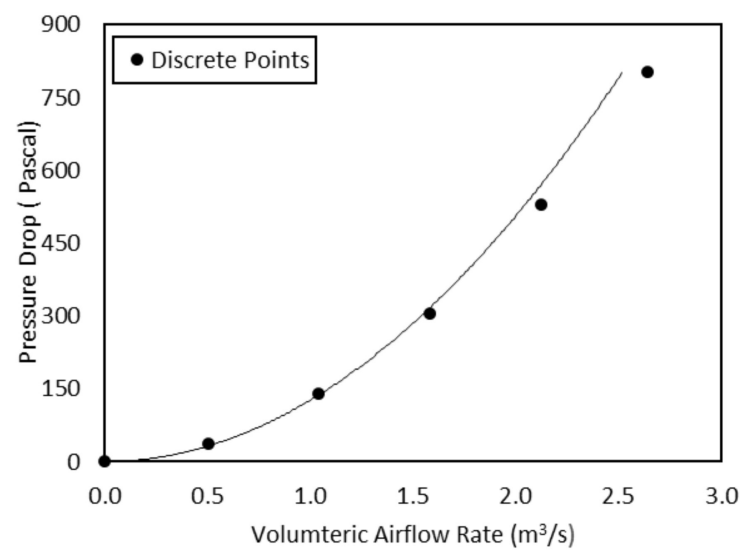

(b)

Figure 2. (a) Linear dependence of airflow speed on the VFD frequency; (b) quadratic dependence of total pressure drop on the airflow through the filter.

\subsection{Iso-Kinetic Sampling and Cleaning Efficiency}

A TSI optical particle spectrometer (OPS) 3330 device was used to sample the airstream for dust particle concentration. The OPS uses a laser to count and size the dust particles. It also has an internal pump that was programmed to run for 5.0 minutes, which was also the sampling duration. The density of coal $\left(1220 \mathrm{~kg} / \mathrm{m}^{3}\right)$ and complex refractive indices (1.78-i 0.60) were programmed into the OPS [28]. Iso-kinetic sampling is the technique of obtaining a representative concentration of aerosols from an airstream without influencing the airflow profile [29]. Sampling nozzles were installed with their inlet facing the airstream. These nozzles were designed based on the computed average diameter when they are 
connected to the OPS using a flexible pitot tube. Figure 3a shows two out of four nozzles used to sample $1.42 \mathrm{~m}^{3} / \mathrm{s}$ and $1.89 \mathrm{~m}^{3} / \mathrm{s}$ of air. Figure $3 \mathrm{~b}$ shows the nozzle installed upstream of the filter and pointing into the airflow. The nozzles were connected to the OPS via a flexible pitot tube. A desiccant dryer was installed downstream of the filter to remove water droplets from the air before being sampled by the OPS.

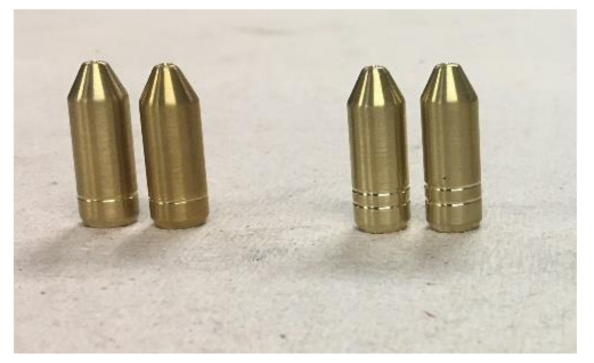

(a)

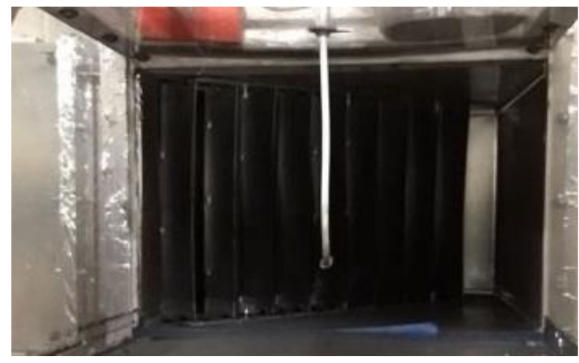

(b)

Figure 3. (a) Iso-kinetic sampling nozzles; (b) sampling nozzles installed upstream.

An auger feeder-type coal dust injection system with an attached dust reservoir was designed and 3D printed. This Arduino-controlled dust feeding mechanism ensured that the dust could be fed without overwhelming the OPS with too many particles which, otherwise, would have led to coincidence errors. This would have led to an incorrect particle count. Holes were drilled at suitable places upstream and downstream of the filter and airflow speed measured at different depths. Iso-kinetic sampling nozzles were installed at these locations facing the airflow.

\section{Results}

The experiments were run by varying the airflows in random order. Raw data of particle concentration by count was downloaded from the OPS. Aerosol management software was used to obtain gravimetric concentrations for all flows. Values obtained by averaging the three repetitions are reported in this manuscript.

\subsection{Dilution of Dust Concentrations at Higher Airflows}

Increasing the airflow through the filter led to a higher dilution of coal dust in the airstream. The OPSs installed upstream and downstream recorded this trend. The upstream OPS reported higher dust concentration compared to the one downstream, the difference in which is the cleaning efficiency for the known particle diameter for the given airflow. Dust concentration decreased upstream and downstream. Figure $4 \mathrm{a}-\mathrm{d}$ show the diminishing dust concentrations downstream as the airflow through the filter increases. This indicates that a higher airflow dilutes the dust concentration to lower values.

\subsection{The Capture of Dust Particles by the Water Spray}

Dust concentration was observed to be alleviated with the water spray operational. Figure 5a,b show the concentration of coal dust particles downstream of the filter for all airflows. The figures show that the OPS detected a much lower dust concentration downstream when the flow through the spray was $22.7 \mathrm{~L} / \mathrm{min}$. For instance, a dust concentration of $4.6 \mu \mathrm{m}$ size downstream diminished to 86 from $1187 \mu \mathrm{g} / \mathrm{m}^{3}$ when the water flow was increased to $22.7 \mathrm{~L} / \mathrm{min}$ from $18.9 \mathrm{~L} / \mathrm{min}$ at $2.83 \mathrm{~m}^{3} / \mathrm{s}$. This could be attributed to the capture of dust mid-flight by the water sprays. Therefore, escaped dust at a much-lower dust concentration is released into the mine atmosphere. This, in turn, will lead to lower exposure of miners. This will also result in a much-reduced deposition of float dust necessitating infrequent rock dusting and other dust alleviation measures. 


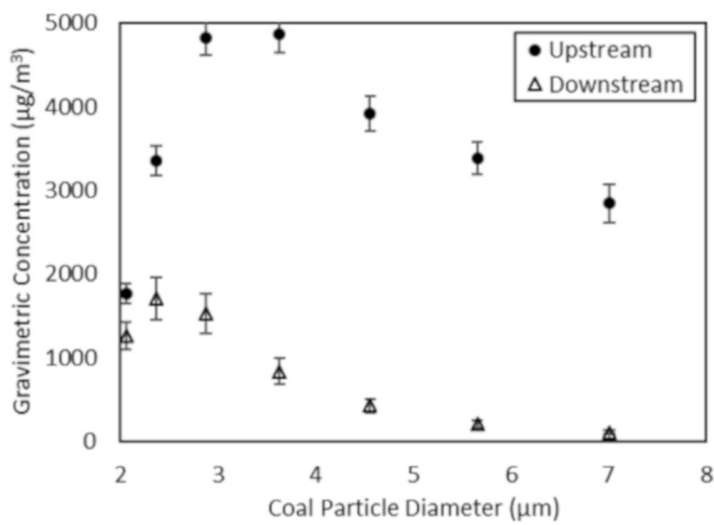

(a)

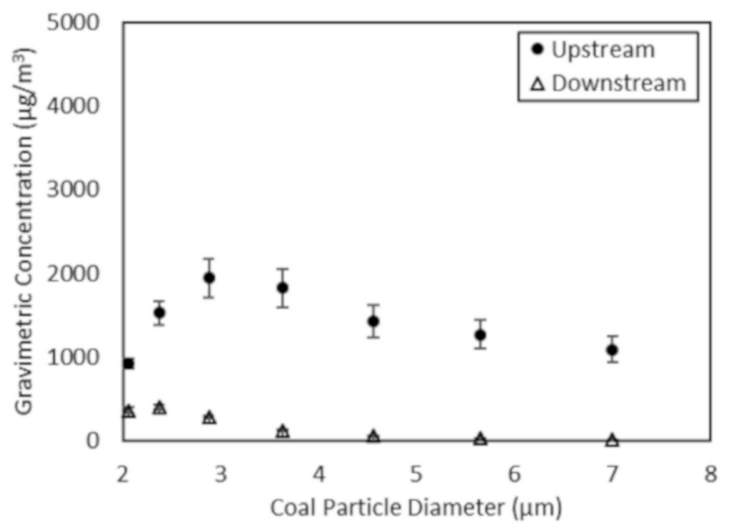

(c)

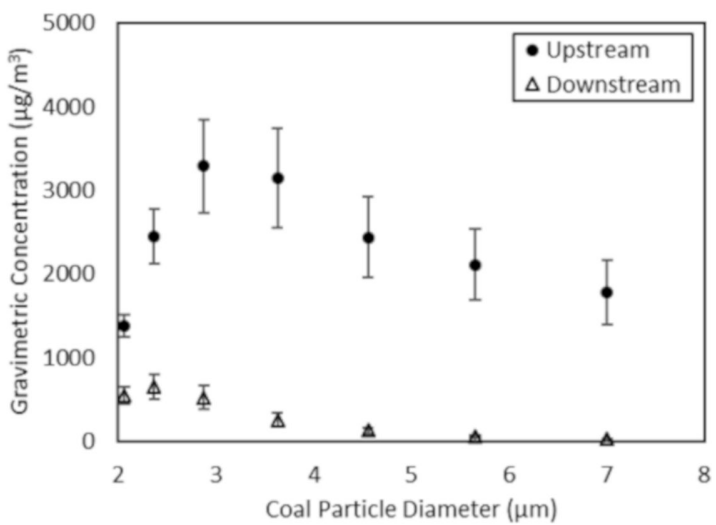

(b)

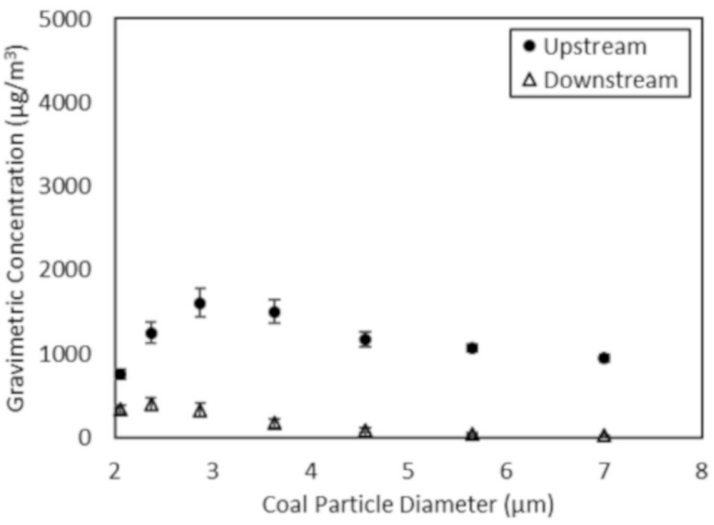

(d)

Figure 4. (a) Dust-concentration difference at $1.42 \mathrm{~m}^{3} / \mathrm{s}$; (b) dust-concentration difference at $1.89 \mathrm{~m}^{3} / \mathrm{s}$; (c) dustconcentration difference at $2.36 \mathrm{~m}^{3} / \mathrm{s} ;(\mathbf{d})$ dust-concentration difference at $2.83 \mathrm{~m}^{3} / \mathrm{s}$ with water flow of $22.7 \mathrm{~L} / \mathrm{min}$.

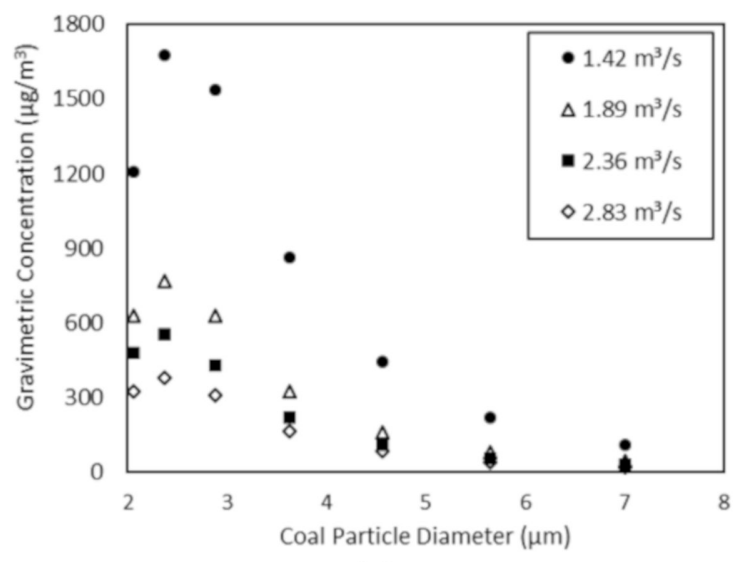

(a)

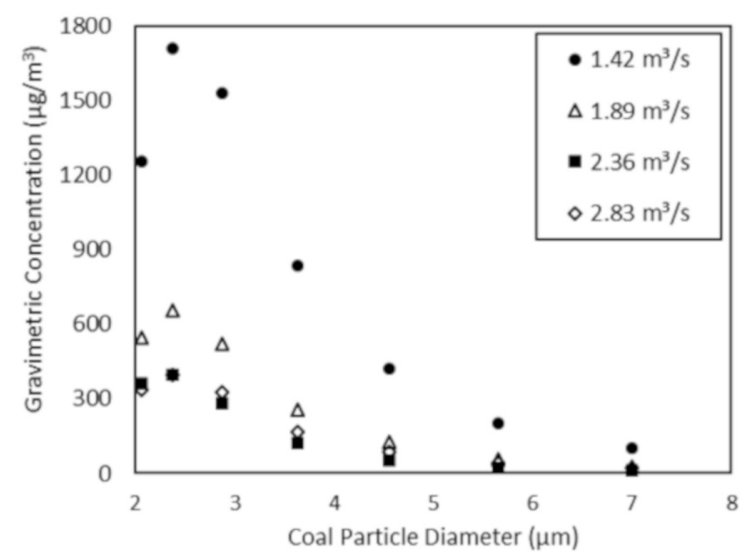

(b)

Figure 5. (a) Dust-concentration downstream with the water inflow of $18.91 / \mathrm{min}$; (b) dust-concentration downstream with the water inflow of $22.7 \mathrm{~L} / \mathrm{min}$.

\subsection{Cleaning Efficiency and Airflow Rate}

The influence of water influx on the cleaning efficiency was also determined. Figure $6 \mathrm{a}, \mathrm{b}$ show the cleaning efficiency for airflow rates of 1.42 and $2.83 \mathrm{~m}^{3} / \mathrm{s}$. Particle removal efficiency improved with an increase in airflow. The plots also indicate that increasing the water flow improved the particle removal efficiency of the filters, although the percentage 
increase was not significant. This further indicates that the particles were captured by the impaction of the particles on the filter surface. Increased water flows from the spray could have led to the capture of dust particles mid-flight before they impacted the filter.

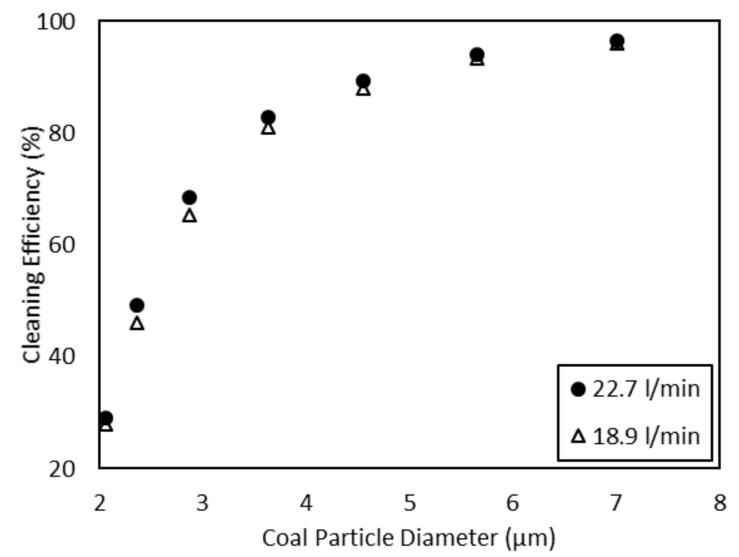

(a)

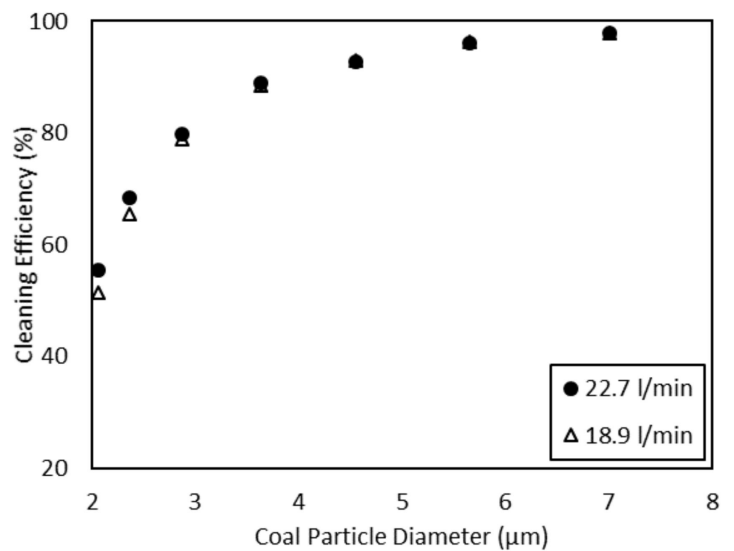

(b)

Figure 6. (a) Cleaning efficiency comparison of the filter at $1.42 \mathrm{~m}^{3} / \mathrm{s}$; (b) cleaning efficiency comparison of the filter at $2.83 \mathrm{~m}^{3} / \mathrm{s}$.

Figure 7a,b show the summary of all experiments run at different air and water flows. Filter cleaning efficiency is improved as the feed particle size increases. Filter cleaning efficiency, in general, also improved with an increase in water influx on the fibrous filter.

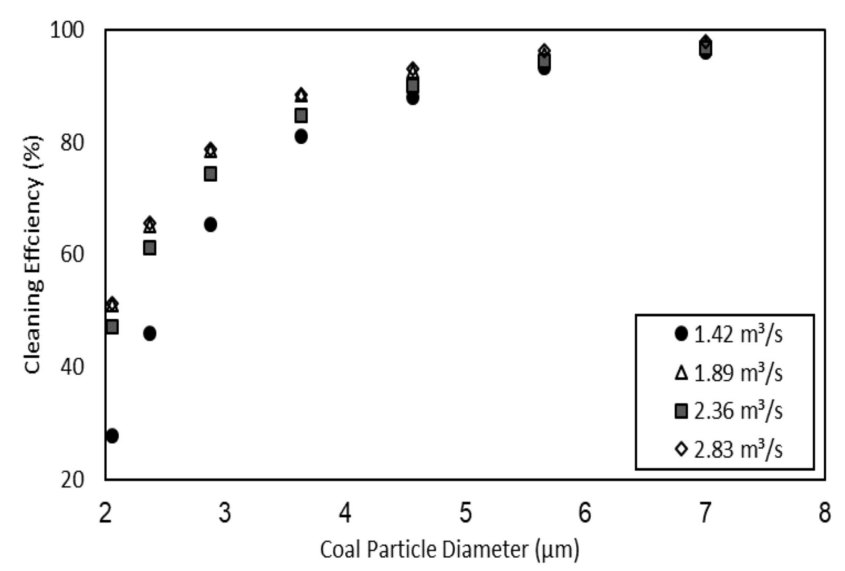

(a)

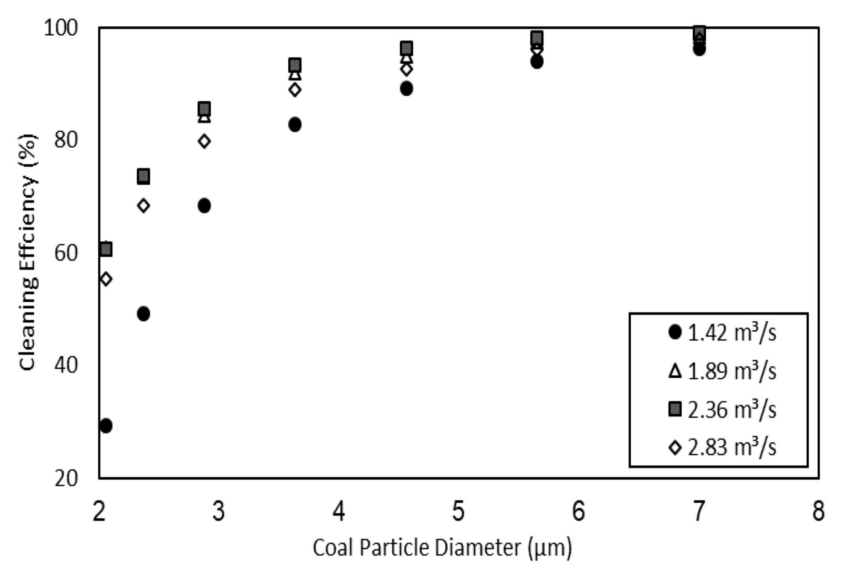

(b)

Figure 7. (a) Cleaning efficiency comparison of the filter with a water inflow rate of $18.9 \mathrm{~L} / \mathrm{min}$ at different airflow rates; (b) cleaning efficiency comparison of the filter with a water inflow rate of $22.7 \mathrm{~L} / \mathrm{min}$ at different airflow rates.

\subsection{Determination of Particle Cut-Off Sizes}

Curves of the form of exponential growth to a maximum as shown in Equation (2) could be fit to most appropriately predict the cleaning efficiency trends. This equation predicts no capture of particles of very small sizes while near-perfect capture of large size particles is predicted.

$$
\eta=a\left(1-e_{-}{ }^{b d}\right)
$$

where the parameters $a$ and $b$ are constants obtained from the best curve fit. The parameter $d$ denotes the aerosol diameter in microns. These parameters were obtained for all values of airflows and water flows. Figure 8 shows the plot of cleaning efficiency at the airflow of $1.89 \mathrm{~m}^{3} / \mathrm{s}$ with water inflow set at $18.9 \mathrm{~L} / \mathrm{min}$. An adjusted $\mathrm{R}^{2}$ value of 0.91 was obtained 
for this curve fit. Equation (1) was used to compute particle cut-off sizes under known air and water flows. Values of $a$ and $b$ were computed and are compiled in Table 1. Efficiency was set at 75 and $90 \%$ to compute the particle cut-off sizes using this equation.

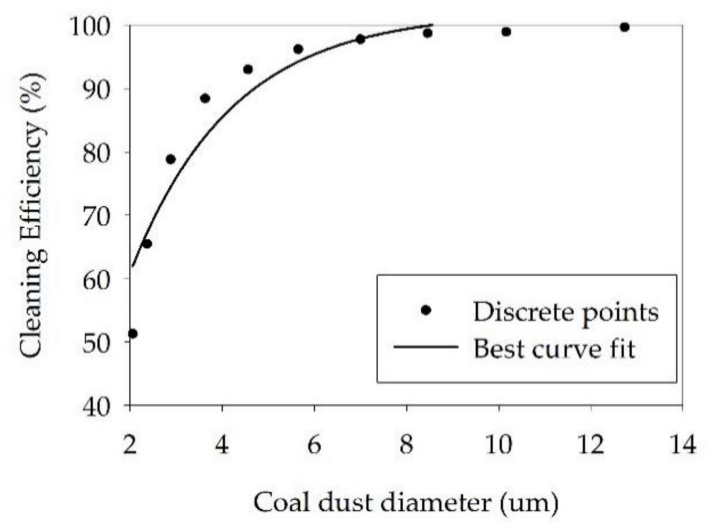

Figure 8. Exponential growth to maximum curve fit for $1.89 \mathrm{~m}^{3} / \mathrm{s}$ (water flow being $18.9 \mathrm{~L} / \mathrm{min}$ ).

Table 1. Calculation of particle cut-off sizes.

\begin{tabular}{ccccccc}
\hline $\begin{array}{c}\text { Airflow } \\
\left(\mathbf{m}^{\mathbf{3}} \mathbf{/ s}\right)\end{array}$ & $\begin{array}{c}\text { Water } \\
\text { Flow } \\
\mathbf{( L / m i n )}\end{array}$ & Parameter, $\boldsymbol{a}$ & Parameter, $\boldsymbol{b}$ & $\begin{array}{c}\text { Particle } \\
\text { Size } \\
\mathbf{d}_{\mathbf{7 5}}(\boldsymbol{\mu} \mathbf{m})\end{array}$ & $\begin{array}{c}\text { Particle } \\
\text { Size } \\
\mathbf{d}_{\mathbf{9 0}}(\boldsymbol{\mu} \mathbf{m})\end{array}$ & ${\text { Adj. } \mathbf{R}^{\mathbf{2}}}$ \\
\hline 1.42 & 18.9 & 107.06 & 4.07 & 4.07 & 6.20 & 0.84 \\
\hline 1.42 & 22.7 & 106.46 & 3.88 & 3.88 & 5.95 & 0.83 \\
\hline 1.89 & 18.9 & 101.90 & 2.95 & 2.95 & 4.76 & 0.91 \\
\hline 1.89 & 22.7 & 101.07 & 2.46 & 2.46 & 4.02 & 0.92 \\
\hline 2.36 & 18.9 & 102.17 & 3.25 & 3.25 & 5.22 & 0.93 \\
\hline 2.36 & 22.7 & 101.74 & 2.41 & 2.41 & 3.90 & 0.91 \\
\hline 2.83 & 18.9 & 102.10 & 2.92 & 2.92 & 4.70 & 0.91 \\
\hline 2.83 & 22.7 & 101.44 & 2.78 & 2.78 & 4.52 & 0.93 \\
\hline
\end{tabular}

\section{Conclusions}

Fibrous filters are used in flooded-bed dust scrubbers to remove coal and rock dust particles close to the active face. Finely woven fibers intercept the smaller particles. Research has shown the scrubbers to lower the dust concentration under controlled conditions. The literature shows that interception and impaction are the predominant filtration mechanisms for a fibrous filter [30]. A test set-up was designed at the University of Kentucky to determine the cleaning efficacy of a fibrous filter for different particle sizes. The cleaning efficiency of a fibrous filter depends primarily on the particle size passing through the filter, the stream velocity, and the water flow rate. Airflow through the filter and water rates were altered systematically to investigate their impact on cleaning performance.

Experiments showed that the fibrous filter captured 75 and $90 \%$ of the particles of sizes 4.07 and $6.20 \mu \mathrm{m}$, respectively, at an airflow of $1.42 \mathrm{~m}^{3} / \mathrm{s}$ through it. The filter performance improved significantly with the particle sizes being reduced to 3.25 and $5.22 \mu \mathrm{m}$ at the airflow of $2.36 \mathrm{~m}^{3} / \mathrm{s}$ and to 2.92 and $4.70 \mu \mathrm{m}$ at the airflow of $2.83 \mathrm{~m}^{3} / \mathrm{s}$. These results were obtained at the water flow rate of $18.9 \mathrm{~L} / \mathrm{min}$. Therefore, larger coal dust particles were captured more efficiently compared to the smaller ones, which could escape the filter. Increasing the water flow rate to $22.7 \mathrm{~L} / \mathrm{min}$ improved the filter performance with the capture of smaller particles. Approximately 75 and $90 \%$ of the particles of size 2.78 and $4.52 \mu \mathrm{m}$ were captured at the airflow of $2.83 \mathrm{~m}^{3} / \mathrm{s}$. A higher water flow leads to more 
pronounced flooding of the filter surface and helps in the alleviation of filter clogging. The film formation assists in the capture of smaller coal dust particles from the airstream.

Author Contributions: Conceptualization, S.S., N.G., and A.R.K.; methodology, A.R.K., N.G.; validation, N.G., A.R.K.; formal analysis, N.G.; investigation, N.G., A.R.K.; resources, S.S.; data curation, N.G.; writing-original draft preparation, A.R.K.; writing-review and editing, S.S.; visualization, N.G.; supervision, S.S.; project administration, S.S.; funding acquisition, S.S., A.R.K. All authors have read and agreed to the published version of the manuscript.

Funding: This research was funded by the National Institute for Occupational Safety and Health, United States This project aims to analyze and develop dust filters for mining applications.

Institutional Review Board Statement: Not applicable.

Informed Consent Statement: Not applicable.

Data Availability Statement: The data presented in this study are available on request from the corresponding author.

Conflicts of Interest: The authors declare no conflict of interest. The funders had no role in the design of the study; in the collection, analyses, or interpretation of data; in the writing of the manuscript, or in the decision to publish the results.

\section{References}

1. Arnold, C. A scourge returns: Black lung in Appalachia. Environ. Health Perspect. 2016, 124, A13-A18. [CrossRef] [PubMed]

2. Blackeley, D.; Halldin, C. Continued increase in lung transplantation for coal workers' pneumoconiosis in the United States. Am. J. Ind. Med. 2018, 61, 621-624. [CrossRef]

3. Blackley, D.; Reynolds, L.; Short, C. Progressive Massive Fibrosis in Coal Miners from 3 Clinics in Virginia. JAMA 2018, 319, 500-501. [CrossRef]

4. Colinet, J. The Impact of Black Lung and a Methodology for Controlling Respirable Dust. Min. Metall. Explor. 2020, 37, 1847-1856. [CrossRef]

5. Doll, N.; Stankus, R.; Barkman, H. Immunopathogenesis of asbestosis, silicosis, and coal workers' pneumoconiosis. Clin. Chest Med. 1983, 4, 3-14.

6. Leso, V.; Fontana, L.; Romano, R.; Gervetti, P.; Iavicolli, I. Artificial Stone Associated Silicosis: A Systematic Review. Int. J. Environ. Res. Public Health 2019, 16, 568. [CrossRef] [PubMed]

7. Potts, J.; McCawley, M.; Jankowski, R. Thoracic Dust Exposures on Longwall and Continuous Mining Sections. Appl. Occup. Environ. Hyg. 1990, 5, 440-447. [CrossRef]

8. Shahan, M.; Seaman, C.; Beck, T.; Colinet, J.; Mishler, S. Characterization of airborne float coal dust emitted during continuous mining, longwall mining and belt transport. Min. Eng. 2017, 69, 61-66. [CrossRef]

9. Burkhart, J.; McCawley, M.A.; Wheeler, R. Particle Size Distributions in Underground Coal Mines. Am. Ind. Hyg. Assoc. J. 1987, 48, 122-126. [CrossRef] [PubMed]

10. Mine Safety and Health Administration. Report of Investigation, Fatal Underground Coal Mine Explosions; United States Department of Labor: Washington, DC, USA, 2001.

11. MSHA, US Department of Labor. Fatal Accident Report_Performance Coal Company, Upper Big Branch Mine; US Department of Labor: Washington, DC, USA, 2010.

12. Mine Safety and Health Administration. Upper Big Branch Mine-South, Performance Coal Company; United States Department of Labor: Washington, DC, USA, 2014.

13. Seaman, C.; Shahan, M.; Mischler, S.E.; Beck, T.W. Design of a water curtain to reduce accumulations of float coal dust in longwall returns. Int. J. Min. Sci. Technol. 2020, 30, 443-447. [CrossRef] [PubMed]

14. Mendoza, L.R.; Sarver, E.; Saylor, J. Removal of DPM from an airstream using micro-scale droplets. Aerosol Air Qual. Res. 2017, 17, 1865-1874. [CrossRef]

15. Tanigawa, Y.; Alloo, R.; Tanaka, N.; Yamazaki, M.; Ohmori, T.; Yano, H.; Salazar, A.; Saito, K. Development of a New Paint Over-Spray Eliminator. In Progress in Scale Modeling; Springer: Dordrecht, The Netherlands, 2008.

16. Toda, K.; Salazar, A.; Saito, K. Automotive Painting Technology; Springer: Dordrecht, The Netherlands, 2013.

17. Kumar, A.; Levy, A.; Schafrik, S.; Novak, T. Computational fluid dynamics modeling and laboratory analysis of aerosol particles' capture on thin swirling water film in a Vortecone. Powder Technol. 2019, 361C, 499-506. [CrossRef]

18. Kumar, A.; Schafrik, S.; Novak, T. Multi-phase computer modeling and laboratory study of dust capture by an inertial Vortecone scrubber. Int. J. Min. Sci. Technol. 2020, 30, 287-291. [CrossRef]

19. Kumar, A.R.; Schafrik, S. Multiphase CFD modeling and laboratory testing of a Vortecone for mining and industrial dust scrubbing applications. Process. Safety Environ. Prot. 2020, 144, 330-336. [CrossRef]

20. Taylor, A. The Redesigned Vortecone: A Maintenance Free Wet Scrubber Device; University of Kentucky: Lexington, KY, USA, 2019. 
21. Campbell, J.; Moynihan, D.; Roper, W.; Wilis, E. Dust Control System and Method of Operation. U.S. Patent US4380353A, 19 April 1983.

22. Colinet, J.; Reed, W.; Potts, J. Report of Investigations 9693; Impact on Respirable Dust Levels When Operating a Flooded-Bed Scrubber in 20-ft Cuts; National Institute for Occupational Safety and Health (NIOSH): Pittsburgh, PA, USA, 2013.

23. NIOSH. Exposure to Silica Dust on Continuous Mining Operations Using Flooded-Bed Scrubbers; Centers for Disease Control and Prevention: Atlanta, GA, USA, 1997.

24. Wedding, W.C.; Novak, T.; Arya, S.; Kumar, A. CFD Modeling of a Flooded-bed Scrubber Concept for a Longwall Shearer Operating in a U.S. Coal Seam. In Proceedings of the 15th North American Mine Ventilation Symposium, Blacksburg, VA, USA, 20-25 June 2015.

25. Agranovski, I.E.; Shapiro, M. Clogging of wet filters by dust particles. J. Aerosol Sci. 2001, 32, 1009-1020. [CrossRef]

26. Wala, A.; Jacob, J.; Huang, G.; Brown, J.; Rangubhotla, L. How scrubbers help ventilate the face during deep cut mining with a blowing curtain, Mine ventilation. In Proceedings of the 10th U.S./North American Mine Ventilation Symposium, Anchorage, AK, USA, 16-19 May 2004.

27. Wala, A.; Vytla, S.; Huang, S.; Taylor, C. Study on the effects of scrubber operations on the face ventilation. In Proceedings of the 12th US/North American Mine Ventilation Symposium, Reno, NV, USA, 9-11 June 2008.

28. Janzen, J. The refractive index of colloidal carbon. J. Colloid Interface Sci. 1979, 69, 436-447. [CrossRef]

29. Wilcox, J. Isokinetic flow and sampling. J. Air Pollut. Control. Assoc. 1956, 5, 226-245. [CrossRef]

30. Centner, P.; Buttner, H.; Ebert, F. Investigation of a Wet Dust Scrubber with a Pneumatic Nozzle: Dust Collection Based on Turbulent Diffusion. Chem. Eng. J. 1989, 12, 439-444. [CrossRef] 